\title{
O DISCURSO E O HUMOR EM MAFALDA: UMA QUESTÃO DE FILIAÇÃO À FORMAC̣ÃO DISCURSIVA ANTICAPITALISTA
}

\author{
Luciane Botelho Martins ${ }^{37}$
}

RESUMO: Buenos Aires, 1963. O cartunista Joaquín Salvador Lavado Tejón, mais conhecido como Quino, cria a personagem Mafalda como objeto de propaganda de uma empresa que vendia eletrodomésticos. As produções, rejeitadas pela empresa, passam a circular, um ano depois, no periódico Primeira Plana. Desde então, Mafalda tornou-se objeto de pesquisa em diferentes campos de saber, principalmente pelas questões de cunho social e político, por ela problematizadas. Pensando, pois, no caráter de atualidade temática da obra, propomos, à luz da Análise do Discurso de filiação francesa, um estudo sobre a posição-sujeito assumida por Mafalda. É importante frisar que o discurso de Mafalda faz emergir no intradiscurso elementos do interdiscurso, os quais estabelecem espaços de contradição que revelam o que Pêcheux designa por contradição apreendida e exibida. Esses lugares de significação/interpretação constituem-se, pois, lugares de excesso na medida em que o humor, sob a forma de absurdo e evidência emerge, temos assim, o humor construído na discrepância entre o estranho e o identificável, contrapondo-se à Ordem e interpelando o sujeito. A partir disso, buscamos compreender como se dá a relação da personagem Mafalda com a Formação Discursiva Anticapitalista, assim denominada devido ao seu caráter de enfrentamento à ideologia socialmente imposta. Para tal, refletimos sobre um arquivo formado por três tirinhas, as quais constituem um recorte da dissertação de mestrado defendida em 2015.

Palavras-chave: Mafalda; humor; formação discursiva; ideologia.

ABSTRACT: Buenos Aires, 1963, the cartoonist Joaquín Salvador Lavado Tejón, known as Quino, creates the character Mafalda as advertisement object to a company which used to sell household appliances. All material, produced and rejected by the company, was used

37 Professora dos anos iniciais no Município de Rio Grande. Mestra em Letras pela Universidade Católica de Pelotas. 
one year later in a newspaper called Primeira Plana. Since then, Mafalda became research object in different fields of study, mainly because of the social and political aspects addressed by her. Thinking about the relevant topic of the comic strips, we propose, in the light of French Discourse Analysis, a study about the subject position assumed by Mafalda. It is important to note that Mafalda's discourse brings out into the intradiscourse some elements of the inter-discourse. They establish contradictions gaps which revels what Pêcheux calls seized and displayed contradiction. The places of signification/understanding are excess places as the humor, like strange and evident forms, emerges. We have, therefore, the humor built in the discrepancy between the strange and the identifiable, in contrast with the order, interpelling the subject. From this on, we try to understand how the relation between Mafalda character and the anti-capitalist discursive formation is. It is so named because of its characteristic of confront with a social ideology imposed. For this, we reflect about a corpus formed by three comic strips. They are part of the Master's thesis defended in 2015.

Keywords: Mafalda, humor, discursive formation, ideology.

\section{Palavras iniciais}

Criada em 15 de março de 1962 (período que antecedeu o golpe de estado na Argentina 1966-1973), Mafalda é o nome da filha primogênita de um casal tradicional de classe média que vive na Argentina. Com seis anos de idade, Mafalda é, aparentemente, uma figura infantil como as demais, no entanto, o que a difere é o discurso que usa para comentar, discutir, questionar e interpelar os adultos em questões ligadas à política e economia, especialmente aquelas que assolam a sociedade da época, em nível mundial. Desse modo, a personagem Mafalda representa o inconformismo com um homem que alimenta a injustiça social, o racismo, as guerras, a construção de armas nucleares e, sobretudo, certas convenções que não teriam razão de ser, segundo ela. Nesse sentido, Mafalda revela seu desejo por um futuro melhor para a humanidade - paz, democracia e respeito aos direitos humanos.

Note-se que, estando o processo de exclusão presente em todos os grupos sociais, temos materializado na obra Toda Mafalda um discurso que aponta à constante luta de classes através da oposição: ricos X pobres, opressores X oprimidos. É, pois, pensando na relação de classes como luta construída sob a forma de evidência, que propomos uma reflexão sobre as 
posições-sujeito assumidas por uma personagem feminina infantil frente ao sistema capitalista, o qual é fundado na contradição dos sentidos de liberdade e igualdade entre todos.

Em vista disso, temos como objetivo neste trabalho mostrar um recorte da dissertação de mestrado defendida em 2015. Nesse recorte, nosso objetivo é mostrar, a partir de um processo analítico-reflexivo sob o prisma da análise de discurso de filiação francesa, o funcionamento discursivo da interrogação, entendendo-a como lugar da falta e do silêncio. Ao pensarmos na interrogação como lugar da falta, estamos tratando de um espaço em que o dizer, por uma questão ideológica, não pode/deve ser dito. Já no que concerne ao lugar do silêncio, estamos tratando-o como uma ausência presente, lugar de produção de sentido. Desse modo, ao considerarmos a falta e o silêncio, na materialidade significante em Mafalda, estamos propondo um estudo da leitura pelo viés da pergunta, o qual apontou a identificação do sujeito com a formação anticapitalista - FDA.

\section{Identificação de Mafalda com a Formação Discursiva Anticapitalista - FDA}

Ao longo do nosso exercício de análise ${ }^{38}$, optamos em denominar a Formação Discursiva de Mafalda como anticapitalista ${ }^{39}$, por tratarmos da relação que o sujeito do discurso estabelece com a FD, nesse caso, uma relação contrária ao pensamento capitalista - FDA. Para tanto, faz-se necessário compreender o que estamos entendendo por formação discursiva, já que o termo também é utilizado por outras teorias, com sentidos diferentes.

A definição inicial do conceito partiu de Foucault (2013), mas foi Maldidier (2003) que, ao refletir sobre o que Foucault inicialmente apontou, elabora sua primeira crítica. Convém lembrar que, na ocasião, a

\footnotetext{
38 Vale ressaltar que a denominação da Formação Discursiva Anticapitalista FDA - não foi dada a priori pelo analista, mas se constituiu a partir de um gesto de leitura.

${ }^{39} \mathrm{O}$ termo anticapitalista foi retirado do artigo O que é (anti)capitalismo?, escrito por Ellen Meiksins Wood, e traduzido pela Profa Lígia Osório Silva IE/Unicamp. Nesse artigo, a autora define o termo em questão como movimento que luta por justiça social, paz, democracia e um ambiente sustentável. Ainda, segundo a autora, trata-se de um campo amplo, do qual outros movimentos derivam, entre eles o socialismo e o comunismo.
} 
autora apresenta três conceitos importantes a serem pensados para uma teoria do discurso. A primeira sobre a própria definição de discurso como conjunto de enunciados pertencentes a uma formação discursiva; a segunda como prática discursiva de caráter extralinguístico; e a terceira, aquela que nos interessa no momento, sobre as formações discursivas como instância reguladora. Sobre essa última, ela destaca que pelo fato de no discurso nada ser fixo e estanque,

[...] guardaremos essencialmente a noção de discurso como uma prática, resultante de um conjunto de determinações reguladas em um momento dado por um feixe complexo de relações com outras práticas, discursivas e não discursivas. Esse complexo de relações para nós deve ser estabelecido no quadro do conjunto articulado dos conceitos do materialismo histórico (MALDIDIER, 2014, p. 86).

Assim, pensar uma teoria materialista do discurso é pensar, sobretudo, no funcionamento da ideologia como prática social que se materializa em nossos dizeres sob a forma de assujeitamento ideológico.

A autora também destaca que, ao considerar que as formações discursivas são componentes das formações imaginárias, Pêcheux, Haroche e Henry apontam uma versão reformulada de enunciação, na qual "o 'sujeito falante' toma posição com relação às representações das quais ele é suporte” (MALDIDIER, 2014, p. 99), representações essas que retornam no enunciado sob a forma de pré-construído.

Seguindo essa linha de pensamento, a inscrição inconsciente de um sujeito em uma formação discursiva ou outra, ou até em mais de uma, é o que Pêcheux chamou de "tomada de posição", e é por essa razão que nossas palavras podem produzir sentidos diferentes em formações discursivas diferentes. Nos termos de Pêcheux, "toda formação discursiva dissimula, pela transparência do sentido que nela se constitui, sua dependência com respeito ao 'todo complexo com dominante' das formações discursivas” (2009, p. 149).

Note-se ainda que a dupla função da ideologia como força social se constitui na arbitrariedade da revelação-ocultação. É, pois, esse caráter arbitrário que garante a eficácia histórica da ideologia. Com base nisso é 
que Haroche, Henry e Pêcheux (1971) afirmam que as formações ideológicas comportam uma ou mais formações discursivas, determinando o que pode/deve ser dito e o que não deve/não pode ser dito. Nesse sentido, o discurso não pode ser compreendido distante da teoria das ideologias, do mesmo modo que a teoria materialista das práticas discursivas não pode ser compreendida numa perspectiva rígida do materialismo histórico, pois isso descaracterizaria o caráter metafórico que lhe é próprio. Pêcheux, então, compreende a formação discursiva como um domínio discursivo a partir do qual há reduplicação da identificação. Nos termos do autor

[...] a tomada de posição resulta de um retorno do "Sujeito" no sujeito [...] $\mathrm{O}$ "desdobramento" do sujeito - como "tomada de consciência" de seus "objetos" é uma reduplicação da identificação, precisamente na medida em que ele designa o engodo dessa impossível construção da exterioridade no próprio interior do sujeito (PÊCHEUX, 2009, p. 160).

Em outros termos, é possível dizer que pela tomada de posição o sujeito identifica-se com seus pares e com a forma-sujeito, processo o qual o autor chama de reduplicação da identificação. É importante observar que esse "ideal homogêneo" do sujeito e das formações discursivas são retomadas por Pêcheux ao longo de suas reflexões. Reflexões essas, que o levam à concepção de um sujeito dividido, clivado, cindido em relação a si mesmo.

Outro aspecto que justifica a aproximação entre discurso e ideologia é a contradição. Como princípio que constitui a heterogeneidade, a contradição não é apenas uma característica inerente ao interdiscurso, ela também está presente na formação discursiva e na forma-sujeito, uma vez que estamos diante de posições-sujeito diversas.

Ao afirmarmos, então, que o discurso de Mafalda faz emergir no intradiscurso elementos do interdiscurso, estabelecendo espaços de contradição através do humor, estamos tratando do que Pêcheux designa por contradição apreendida e exibida. Esses espaços, lugares de significação, lugares de interpretação, constituem-se, pois, lugares de 
excesso na medida em que o humor, sob a forma de absurdo e evidência ${ }^{40}$, funda-se na contradição. Pêcheux, ao tratar da contradição, afirma que:

[...] quer o sujeito, em toda sua ignorância, se submeta a ela, quer ao contrário, ele a apreenda por meio de sua agudeza de "espírito": um grande número de brincadeiras, anedotas etc., são, de fato, regidas pela contradição inerente a essa discrepância; elas constituem como que sintomas dessa apreensão e tem como sustentáculo o círculo que liga a contradição sofrida (isto é, a "estupidez") à contradição apreendida e exibida (isto é, a "ironia"), como o leitor poderá com base neste ou naquele exemplo que seja particularmente "eloquente" (2009, p. 142).

Por essa razão, podemos dizer que o humor, construído na discrepância entre o estranho e o identificável, contrapõe-se à Ordem ${ }^{41}$. É ela que interpela o sujeito e apaga a contradição que o constitui e constitui o sentido. O humor, geralmente, expõe a contradição inerente ao sujeito e ao sentido num processo de desnaturalização do que se tornou evidente historicamente. Segundo Pereira, "é inquestionável o fato de que o humor decorre de uma contradição, tese expressa desde os primórdios da estética" (1994, p. 53).

O humor, tomado como contradição, recebe o caráter de agente de mudanças sociais e políticas, pois, aliado à pergunta, torna explícita uma série de diferenças ideológicas, algumas delas sedimentadas no

\footnotetext{
40 Ao tratar de absurdo e evidência, Pêcheux reitera que esse retorno do que é estranho no familiar é um efeito do pré-construído. Nas palavras do autor, "esse efeito de pré-construído consistiria numa discrepância pela qual um elemento irrompe no enunciado como se tivesse sido pensado 'antes, em outro lugar, independentemente" (2009, p. 142).

${ }^{41}$ Submeter o sujeito à ordem diz respeito ao processo de assujeitamento a que todo sujeito está submetido à ordem da língua, à ordem do Outro (inconsciente) e à ordem da ideologia, visto que o assujeitamento se dá pela língua.
} 
discurso do Outro. Segundo Pereira, "a função do humor é [...] relatar os defeitos escondidos, mostrar o objeto de riso exterioridade e inconsistência" (1994, p. 54). Dessa forma, temos, no humor em questão, uma tentativa de burlar, de contrapor, de romper com uma determinada ideologia. Ao pensarmos, pois, sobre o humor em Mafalda, podemos notar que esse se dá quase que exclusivamente na esfera política. Passemos, então, à análise da primeira tirinha:

(01) Primeira tira analisada - $\mathrm{SDR}^{42} 1$ :
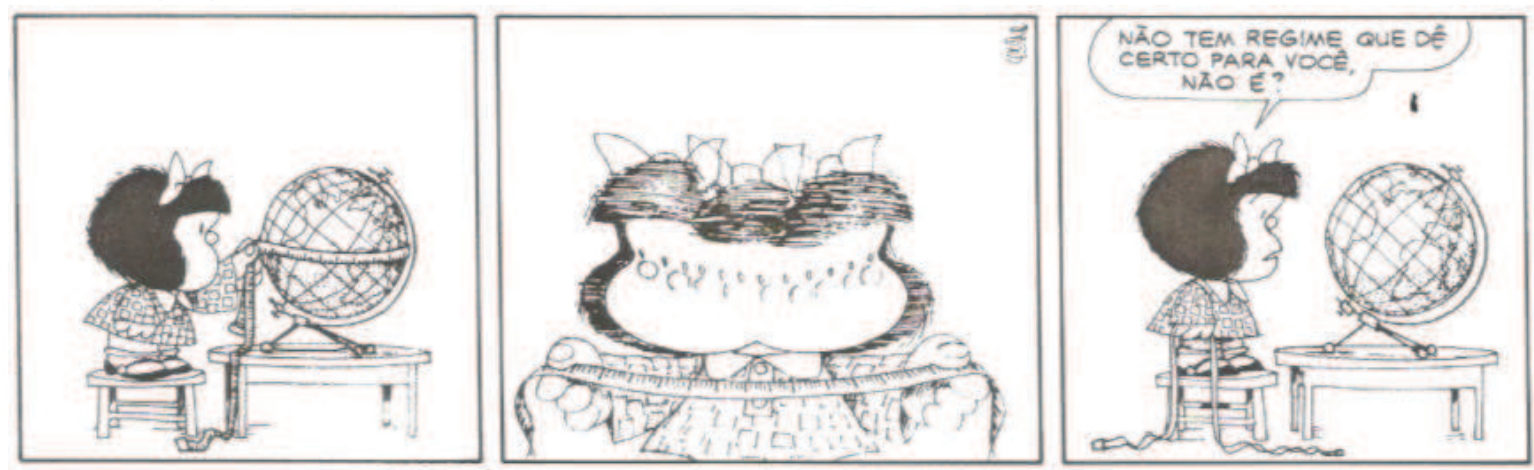

(QUINO, 2010.p. 194)

Nessa tirinha, temos um sujeito inquieto frente ao Mundo, metonimicamente representado pelo globo terrestre. A figura do globo, no centro da mesa, produz um sentido de centralidade, isto é, o mundo e seus problemas de ordem política, ambiental e social constituem-se como o centro das preocupações do sujeito que enuncia. Como podemos observar, no primeiro quadro, o sujeito encontra-se de pé sobre um banco. O gesto da personagem - subir no banco - revela as dificuldades para se alcançar certos objetivos, neste caso, o objetivo da protagonista é examinar o globo (o mundo). Diante do mundo, a protagonista se vê frente ao desafio de medir, quantificar ou ainda qualificar o objeto. Esse sentido é produzido pela ação da protagonista ao utilizar uma fita métrica para medir o globo terrestre. A fita métrica - instrumento utilizado para medir a distância entre pontos - produz um efeito de objetividade e credibilidade aos resultados que aponta. Outro aspecto, ainda do

\footnotetext{
42 Estamos entendendo por SDR, sequências discursivas de referência, ou seja, "sequências orais ou escritas de dimensão superior à frase" (Courtine, 2009, p.55). Em outros termos, as sequências discursivas estão funcionando nesta pesquisa como pontos de referência, os quais levam em conta elementos linguísticos e extralinguísticos, constituindo dessa forma nosso corpus discursivo de análise.
} 
primeiro quadrinho e que merece nossa atenção, diz respeito à ausência do traçado da boca da personagem. Essa ausência nos faz refletir sobre o silêncio fundante, aquele que, segundo Orlandi (2007), encontra-se na base de todo dizer. Desse modo, o discurso produz sentidos.

Ao passarmos para o segundo quadrinho, temos um discurso produzido só a partir da imagem, assim como do anterior. Trata-se de uma figura sinérgica, isto é, uma figura que reproduz movimento. Nesse caso, o movimento aponta concomitante e equivocamente para a constatação de que a distância entre os pontos se configura como problema de "grande" proporção e para o gesto de negação. Desse modo, a não aprovação da dimensão do problema constatado, associada ao gesto de negar a referida constatação, produz um efeito denominado por Indursky (1990) como denegação discursiva.

O termo denegação tem sua origem na psicanálise. De acordo com Indursky, a denegação discursiva acontece quando "o sujeito diz sem, de fato, dizer, apresentando-se dividido entre seu desejo de dizer e sua necessidade de recalcar" (1990, p. 118). Assim, a denegação discursiva se dá quando uma negação "incide sobre um elemento de saber próprio à FD que afeta o sujeito do discurso" (1990, p. 120).

O mesmo processo de denegação discursiva pode ser observado no enunciado verbal ${ }^{43}$ do terceiro quadro Não tem regime ${ }^{44}$ que dê certo para você, não é? Isso porque, ao enunciar "Não tem" o sujeito recalca o enunciado afirmativo contrário "Tem". Note-se ainda que, no enunciado apresentado em forma de pergunta, uma pista que contribui,

${ }^{43} \mathrm{O}$ enunciado verbal tal qual está sendo tomado neste trabalho segue a leitura de Courtine (2009), que ao retomar o conceito de "formulação enunciativa" de Foucault (2013) produz uma ressignificação do termo, ou seja, o autor propõe uma divisão em que o "elemento de saber de uma Formação Discursiva" passa a chamar-se Enunciado [E] e as formulações passam a ser reconhecidas como enunciado [e]. Em outros termos [E] representa o interdiscurso, enquanto [e] representa o intradiscurso. Assim, entendemos como enunciado verbal a materialidade do discurso na linearidade. Foi partir do conceito de enunciado verbal, que Quevedo (2012) propôs o conceito de enunciado visual, segundo ele "um elemento, uma constituinte da SD - aquilo que chamamos de "parte significativa"”(p. 147), enunciado [e] pode também ser tomado a partir de uma imagem. Nasce assim, o conceito de enunciado visual.

$44 \mathrm{O}$ termo regime apontado na tirinha, devido às condições de produção do discurso, refere-se ao regime militar na Argentina, o qual teve duração de oito anos (1966 a 1973). 
significativamente, para a produção de sentido é o excesso do termo negativo "não", associado ao gesto anterior da protagonista. $\mathrm{Na}$ perspectiva discursiva, o excesso é tratado por Ernst como um "acréscimo necessário" (2009, p. 04), que busca a "reiteração incessante de determinados saberes interdiscursivos", com vistas a manter os mesmos pressupostos ideológicos.

O excesso da negação enfatiza duas posições-sujeito, uma ligada ao senso comum (o mundo não tem jeito) e outra ligada a uma FD anticapitalista, que proporia um regime que desse certo. Isso significa dizer que a reiteração do gesto negativo sobre a impossibilidade de mudança do mundo recalca o pressuposto afirmativo, que se constitui num saber pertencente ao que estamos chamando de FD anticapitalista.

Um outro aspecto a ser considerado diz respeito ao funcionamento da interrogação. Pragmaticamente, esse funcionamento implica uma injunção à resposta; discursivamente, à interpretação. Nesse caso, o sujeito-enunciador convoca seu interlocutor, representado na figura do globo terrestre, a assumir uma posição-sujeito frente ao regime vigente.

É, pois, pela equivocidade do termo "regime", pela reiteração da negação e pela interrogação que o sujeito enunciador assume uma posição contrária ao regime vigente e tudo o que ele representa para a sociedade.

(02) Segunda tirinha analisada (SDR02):
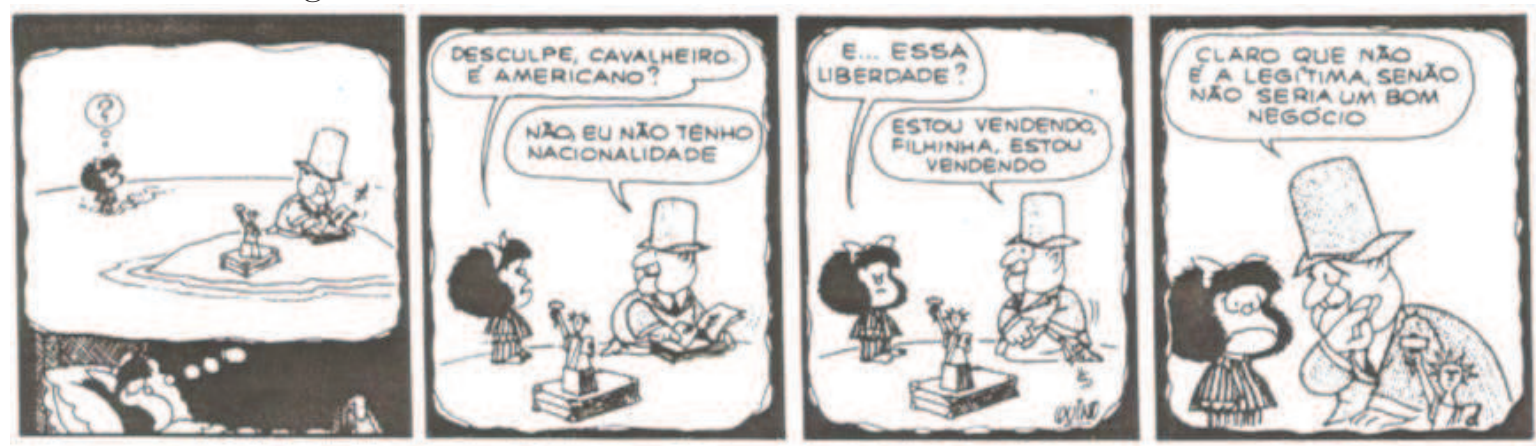

(QUINO, 2010.p. 208)

$\mathrm{Na}$ segunda sequência discursiva desta pesquisa temos, no primeiro quadro a imagem da protagonista que, enquanto dorme, sonha. Esse sonho mostra a inquietação - materializada no ponto de interrogação - do sujeito diante da cena de um personagem solitário, preocupado com o dinheiro que conta. Ainda compondo a imagem, figura uma réplica da Estátua da Liberdade, em dimensões reduzidas, se 
comparada tanto com a imagem original quanto com a outra personagem, que se encontra na possível ilha de Manhattan. Essa personagem apresenta índices que apontam para a figura do Tio $\mathrm{Sam}^{45}$, como a cartola $^{46} \mathrm{e}$ o terno. Entretanto, faltam na cartola as listras e as estrelas que remetem à bandeira dos Estados Unidos, o que implica um efeito de sentido de desidentificação com a nacionalidade americana.

Podemos observar, então, que a primeira imagem produz um sentido sobre o capitalismo, o de sistema que individualiza os sujeitos, dando-lhes a falsa ideia de liberdade, já que, pelo sistema, os indivíduos tornam-se sujeitos assujeitados ao capital e à mais valia. Note-se que, nesse primeiro quadro, os sentidos são produzidos pela imagem que fazemos da imagem (objeto empírico), isso porque, conforme Quevedo, a imagem

[...] é a produção de uma leitura; um gesto de interpretação que, como tal, representa um ponto de recorte nos continua de sentidos, com cuja versão o sujeito se identifica. Versão essa que se lhe "naturaliza", "evidencia", apresenta como universal... (2012, p. 111, grifo do autor).

Ao passarmos para a segunda cena, podemos observar que o discurso funciona sob a forma de um pré-construído na pergunta $E$ americano?. Através da pergunta, o saber de que os EUA é um modelo do sistema capitalista surge na linearidade, compondo o intradiscurso. Desse modo, se, do ponto de vista pragmático, temos uma injunção à resposta afirmativa do outro, do ponto de vista discursivo o sentido produzido é de que o domínio capitalista é uma marca do país americano e através dele se perpetua, principalmente pela relação que estabelece com os demais países.

No mesmo quadro, podemos notar ainda que, ao produzir uma dupla negação - Não, eu não tenho nacionalidade -, o sujeito recalca/faz omitir sua nacionalidade, apontando para a condição daqueles "cartolas" cujos negócios ultrapassam as fronteiras americanas, atingindo outros

45 Essa figura é a personificação nacional dos Estados Unidos da América. Constitui-se num dos símbolos mais conhecidos do mundo. Surgiu durante a Guerra angloamericana em 1812.

46 O termo "cartola", tanto em inglês quanto em português, implica status e poder. 
países e controlando o mundo. Na realidade, a personagem representa o capital, o mercado. Por isso, não tem nacionalidade.

Dando sequência a essa análise, passamos ao terceiro quadro, no qual o sujeito, ao enunciar E... essa liberdade?, reitera o sentido de que os EUA são um representante do capitalismo mundial. Note-se que as reticências, como lugar do excesso, isto é, como espaço significante, apontam para os sentidos em torno do termo liberdade, metonimicamente representada pela Estátua da Liberdade. Podemos perceber também que a utilização do pronome demonstrativo, antes do substantivo "liberdade", produz um efeito reificador e depreciativo sobre o termo. Estamos, então, diante de três sentidos para o termo liberdade: liberdade como objeto de mercado; liberdade como sinônimo de ser livre; e liberdade como símbolo dos EUA. Desse modo, os sentidos são produzidos a partir do equívoco em torno do que é liberdade. Esse equívoco, em seu caráter contraditório, é que produz o efeito de humor na tira.

Vale destacar ainda que, através do funcionamento da pergunta, ao refutar o sujeito-Mafalda, o seu interlocutor produz um enunciado marcado pela repetição - Estou vendendo filhinha, estou vendendo. Essa repetição, esse excesso, funciona como uma forma de legitimar o saber da FD capitalista de que a tudo é possível atribuir um valor em dinheiro. Essa é a lógica capitalista. Do mesmo modo, esse sentido é mantido no último quadrinho, pois, vender a legítima liberdade significaria por fim às relações de dependência entre os países mais pobres e as grandes potências, nesta tirinha, representada pelos EUA.

Ao finalizar a análise dessa tirinha, é importante atentar para o silêncio constitutivo da imagem de Mafalda, pois é, também, através desse silêncio, que ela revela uma posição-sujeito contrária aos pressupostos do capitalismo e aos efeitos que essa ideologia produz.

(03) Terceira tirinha analisada (SDR3):
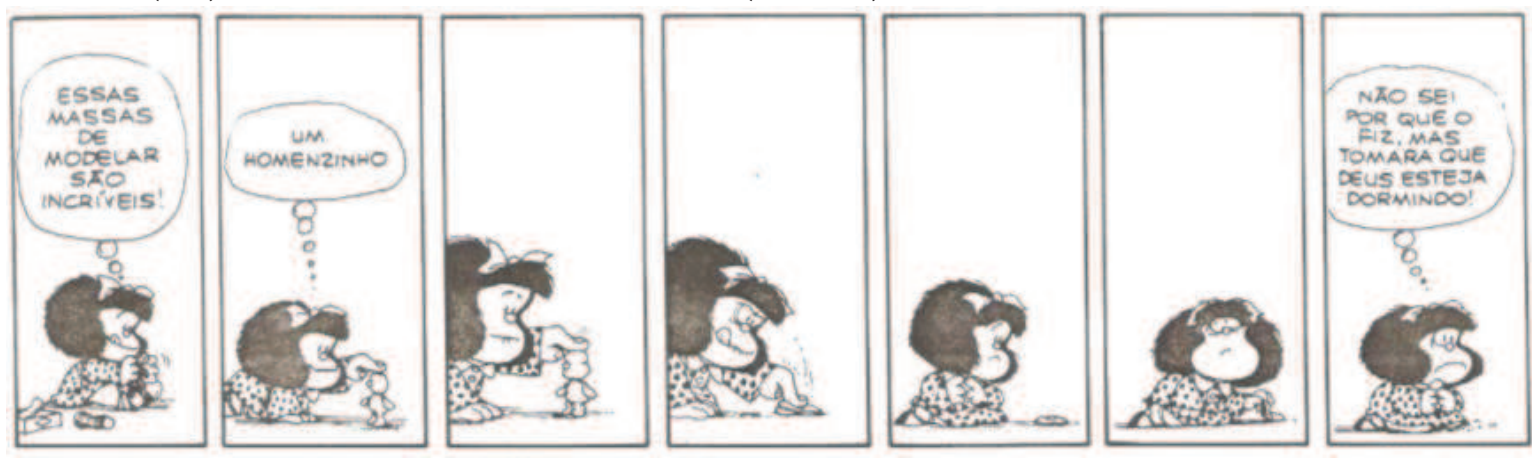

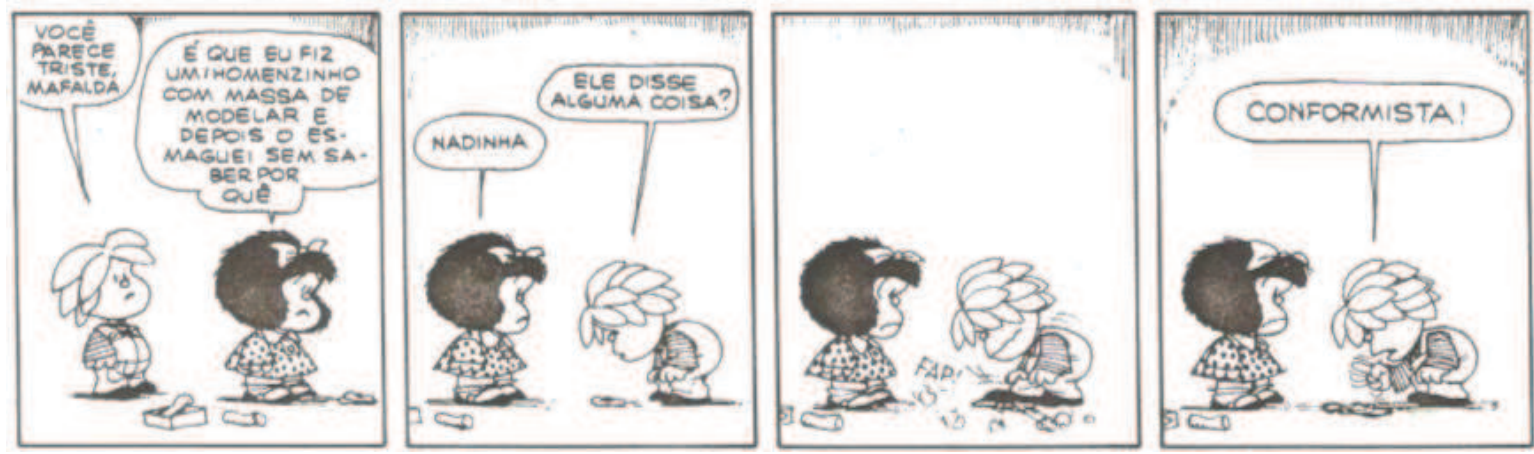

(QUINO, 2010, p. 263)

Nessa terceira sequência discursiva, temos uma tirinha formada por onze cenas. $\mathrm{Na}$ primeira, os sentidos apontam para a inocente brincadeira de criança - manuseio de massinha de modelar. No entanto, ao passarmos para a segunda cena, a personagem, ao construir a figura de um homem, denomina-o como homenzinho. Percebemos, assim, que o acréscimo do sufixo -inho ao termo homem atribui-lhe não apenas um sentido de pequenez em relação ao tamanho, mas também um sentido de pequenez em relação ao seu valor. Assim o termo homenzinho é construído como caráter depreciativo de humanidade.

Dando continuidade à análise, nós observamos uma sequência de duas cenas em que a personagem é colocada em um plano superior, em relação à figura moldada. Trata-se da relação de poder que se estabelece entre o opressor e o oprimido. Pela relação de poder que o contexto oportuniza, a personagem é impulsionada a esmagar o outro. Nosso gesto de leitura é de que, enquanto sujeitos constituídos pelas condições de produção, os sujeitos são levados a exercer o poder sobre o outro, muitas vezes de forma inconsciente, visto que, nas duas imagens seguintes, a personagem expressa pelo seu silêncio um certo arrependimento. Mas por que "certo" arrependimento?

Se observarmos o enunciado verbal Não sei por que o fiz, mas tomara que Deus esteja dormindo!, podemos perceber que o arrependimento não se dá de forma consciente pelo sujeito, mas pelo temor que tem em relação ao olhar do Outro/Deus. Assim, somos sujeitos assujeitados ao olhar do outro/Outro; nosso dizer e nosso fazer não são nossos, mas construídos a partir das formações imaginárias, isto é, daquilo que imaginamos ser o desejo do Outro (instância reguladora), como designa Lacan. Torna-se relevante observar que o enunciado demonstra o desejo do sujeito de escapar do olhar regulador do Outro - que Deus esteja dormindo. De acordo com Orlandi, o discurso religioso caracteriza-se como: 
[...] aquele em que fala a voz de Deus, começaria por dizer que, no discurso religioso, há um desnivelamento fundamental na relação entre locutor e ouvinte: o locutor é do plano espiritual (o Sujeito, Deus) e o ouvinte é do plano temporal (os sujeitos, os homens) [...] $\mathrm{O}$ locutor é Deus, logo, de acordo com a crença, imortal, eterno, infalível, infinito e todo-poderoso; os ouvintes são humanos, logo, mortais, efêmeros falíveis, finitos, dotados de poder relativo. $\mathrm{Na}$ desigualdade, Deus domina os homens (2011, p. 243).

Percebemos que a formação discursiva religiosa é constituinte do sujeito em Mafalda não apenas pelo que diz, mas por sua expressão na imagem (empírica), uma expressão desconcertante e de aparente arrependimento, que se justifica através do enunciado verbal ...eu fiz um homenzinho com massa de modelar e depois o esmaguei sem saber por quê. Com base nessa materialidade linguística, nosso gesto de leitura nos permite dizer que o fato de o sujeito assumir não saber o porquê de sua atitude aponta para o funcionamento da interpelação ideológica, nesse caso, a capitalista, em que aos seres são atribuídos valores de mercado, o que lhes possibilita o exercício do poder uns sobre os outros, a fim de perpetuar a diferenças entre as classes: opressor X oprimido, uma ideologia contrária e ao mesmo tempo contraditória ao que prega o discurso religioso, o de que todos os sujeitos são iguais devendo obediência a Deus, somente.

Essa relação conflituosa entre as classes torna-se evidente, também, no nono quadrinho, quando a personagem Guile questiona se o homenzinho disse alguma coisa. A materialidade nos revela o que Pêcheux afirma que é por meio da língua que o sujeito é assujeitado ideologicamente. Nas palavras do autor:

[...] a modalidade particular do funcionamento da instância ideológica quanto à reprodução das relações de produção consiste no que se convencionou 
chamar interpelação, ou o assujeitamento do sujeito como sujeito ideológico, de tal modo que cada um seja conduzido, sem se dar conta, e tendo a impressão de estar exercendo sua livre vontade, a ocupar o seu lugar em uma ou outra das duas classes sociais antagonistas do modo de produção (ou naquela categoria, camada ou fração de classe ligada a uma delas) (1997, p. 165-166).

Assim, na nona cena da tirinha, ao termos a figura de um homem que cala, que aceita livremente sua condição de subjugado, temos um sujeito que assume sua posição de inferioridade na relação de classes, assume o lugar de oprimido. Um lugar que do ponto de vista do opressor é visto como o lugar do conformismo.

\section{Tecendo o fechamento}

As sequências discursivas que compõem esta pesquisa produzem um efeito de sentido de enfrentamento aos pressupostos que constituem o sistema capitalista. Na SDR1, por exemplo, podemos observar que, por meio da denegação e do excesso, o sujeito toma uma posição. Em outras palavras, temos, através da interrogação, uma posição-sujeito que se identifica com o saber de que não há um sistema que dê conta dos problemas sociais que assolam o mundo, decorrentes do sistema capitalista.

No que se refere à SDR2, observamos que ocorre uma posição de crítica ao sistema capitalista, dado o caráter contraditório do discurso do outro (interlocutor de Mafalda na tira) que, ao omitir sua nacionalidade, revela a perda da identidade americana, consequência da expansão do sistema capitalista, que extrapolou as fronteiras do próprio país. A contradição, expressa pela repetição e pela denegação, é construída a partir do conceito de comércio e liberdade. Aparentemente independentes, esses dois elementos, quando postos juntos, constroem o sentido de que o capitalismo põe em risco a liberdade do outro. Assim, a Estátua da Liberdade como metonímia de uma grande potência (EUA), coloca-se no lugar daquele que vende uma falsa liberdade para o outro (países subdesenvolvidos), à medida que o subjuga, mantendo, assim, uma relação de dependência entre o país que domina e os países dominados. 
Quanto à SDR3, podemos afirmar que temos, visivelmente, através do jogo imagem/palavra, a luta de classes entre oprimidos e opressores, funcionando inconscientemente no sujeito, por meio da pergunta indireta. A análise nos possibilita perceber que, ao questionar-se, Mafalda revela sua interpelação, seu assujeitamento à ideologia capitalista e religiosa. Desse modo, a pergunta que a personagem faz a si mesma é índice de uma posição-sujeito que se encontra em conflito, devido ao seu duplo assujeitamento, de um lado, dado pelos pressupostos capitalistas e, de outro, pelo assujeitamento à ordem divina.

Desse modo, podemos afirmar que, a partir da materialidade significante (tiras de Mafalda) há um funcionamento discursivo que aponta à identificação do sujeito com a FDA. Nos três casos analisados, há a reiteração de uma posição-sujeito de conflito e enfrentamento aos pressupostos do capitalismo, marcado principalmente pela contradição expressa sob a forma de humor e pelos questionamentos que propõe.

\section{REFERÊNCIAS}

ERNST, Aracy. A falta, o excesso e o estranhamento na constituição/interpretação do corpus discursivo. SEAD 2009. Disponível em:

$<$ http://www.ufrgs.br/analisedodiscurso/anaisdosead/4SEAD/SIM POSIOS/AracyErnstPereira.pdf. >Acesso em: 10 jun.2015.

FOUCAULT, Michel. A arqueologia do saber. Tradução de Luiz Felipe Baeta. 8a ed. Rio de Janeiro: Forense Universitária, 2013.

HAROCHE, C. et al. La sémantique et la coupure saussurienne: langue, langage, discours, Langages. Paris, 24, 1971.

INDURSKY, Freda. Polêmica e denegação: dois funcionamentos discursivos da negação. Cadernos de Estudos Linguísticos, no 19, jul/dez. Campinas: IEL/Unicamp, 1990.

. Da heterogeneidade do discurso à heterogeneidade do texto e suas implicações no processo da leitura. In: ERNST-PEREIRA, Aracy; FUNCK, Susana Bornéo (Orgs.). A leitura e a escrita como práticas discursivas. Pelotas: Educat, 2001.

MACHADO, Graciene de Ávila. 1968: ideologia e contestação através das tiras da Mafalda. 2009. 70f. Trabalho de Conclusão de Curso (graduação) - Instituto de Filosofia e Ciências Humanas. Curso de 
História: Licenciatura, UFRGS, Porto alegre, RS. Disponível em: http://hdl.handle.net/10183/21324. Acesso em: 13 jun. 2015. MAFALDA ONLINE. Disponível em: <http://www.mafalda.net/index.php/PT/> Acesso em: 15 jun.2015.

MALDIDIER, Denise. A inquietação do discurso: (Re)ler Michel Pêcheux hoje. Tradução de Eni P. Orlandi. Campinas: Pontes, 2003.

MALDIDIER, D et al. Discurso e Ideologia: bases para uma pesquisa. In: ORLANDI, Eni (org.) Gestos de Leitura: da história no discurso. 4a ed. Campinas: Unicamp, 2014, p. 69-105.

ORLANDI, Eni Puccinelli. As formas do silêncio. No movimento dos sentidos. 6a ed. Campinas: Unicamp, 2007.

. A linguagem e seu funcionamento: as formas do discurso. $6^{a}$. ed. Campinas, SP: Pontes, 2011.

PÊCHEUX, Michel (1969). Análise Automática do Discurso (AAD-69). In: GADET, Françoise; HAK, Tony. (Org.). Por uma análise automática do discurso: uma introdução à obra de Michel Pêcheux. 3a ed. Campinas: Unicamp, 1997.

PÊCHEUX, Michel; FUCHS, Catherine (1975). A propósito da Análise Automática do Discurso: atualização e perspectivas. [trad.] Péricles Cunha. In: GADET, Françoise; HAK, Tony. (Org.). Por uma análise automática do discurso: uma introdução à obra de Michel Pêcheux. 3a ed. Campinas: Unicamp, 1997.

PÊCHEUX, Michel. Semântica e Discurso: uma crítica à afirmação do óbvio. 4a ed. Campinas. SP: Editora Unicamp, 2009.

PEREIRA, ARACY E. Na inconsistência do humor, o contraditório da vida: o discurso proverbial e o discurso das alterações.1994. 181f. Tese (doutorado) - Instituto de Letras e Artes, Pontifícia Universidade Católica do Rio Grande do Sul, Porto Alegre, 1994.

QUEVEDO, Marchiori Q. de. Do gesto de reparar a(à) gestão dos sentidos. Um exercício de análise da imagem com base na Análise do Discurso. 2012. 253 f. Dissertação. (Mestrado em Letras Linguística Aplicada) Universidade Católica de Pelotas. Pelotas, 2012.

QUINO. Toda Mafalda: da primeira à última tira. São Paulo: Martins Fontes, 2010. - Mafalda Inédita. São Paulo: Martins Fontes, 2013. 
O discurso e o humor em Mafalda:

uma questão de filiação à formação discursiva anticapitalista | 113

WOOD, Ellen Meiksins. "O que é (anti) capitalismo."Revista Crítica Marxista, V.17 (2003). Disponível em: http://www.ifch.unicamp.br/criticamarxista/arquivos biblioteca/ artigo99artigo2.pdf. Acesso em: 09 ago. 2015.

Recebido em: 08/10/2018

Aceito em: 13/11/2018 